\title{
Hencher S: Practical engineering geology
}

\author{
Jörg Matschullat
}

(C) Springer-Verlag Berlin Heidelberg 2013

\section{2 | Spon Press, CRC Press | 450 pp | Hardback ISBN 978-0-415-46908-1 USD 195.00; GBP 120.00 | Paper- back 978-0-415-46909-8 USD 79.95; GBP 45.00}

In the phases of design, management, and construction of civil engineering projects, engineering geologists draw on a gamut of knowledge in all areas of Earth sciences. The book provides a detailed view of the work of engineering geologists in this context. Beginning by outlining the basic tasks and skills that engineering geologists need to perform and know, Steve Hencher emphasizes how engineering geologists can make significant contributions at any project onset by ensuring that risks are properly communicated during the initial planning and design project phases. "The engineering geologist will almost always work in a team and needs to take responsibility for his role within that team. If there are geological unknowns and significant hazards, he needs to make himself heard using terminology that is understood by his engineering colleagues..."

The various steps involved with civil engineering projects are described, beginning with the various management tasks of the owners, engineers, architects, and contractors, as well as the business contracts they deal with, albeit from a UK perspective. Chapter 3 "Geology and ground models" points the necessity of simplified representations of a site, as well as the ground investigation and testing.

In Chapter 4, Hencher explains how site investigation (including sub-surface ground investigation) should focus on the needs of the particular project. He outlines concisely

J. Matschullat $(\square)$

Interdisciplinary Environmental Research Center, TU

Bergakademie Freiberg, Brennhausgasse 14, 09599 Freiberg,

Germany

e-mail: joerg.matschullat@ioez.tu-freiberg.de its scope and stages and also advocates that such environmental factors such as in situ stresses, natural gases, seismicity, anthropogenic influences, groundwater chemistry, groundwater pressure, ice, and biogenic factors should be viewed separately from the basic geology. As well, the book describes the various environmental hazards that need to be considered such as landslides, coastal recession, subsidence, settlement, contaminated land, and earthquakes.

In Chapter 5 "Geotechnical parameters" and Chapter 6 "Analysis, design and construction" the essential aspects to consider in ground models and testing are covered. Numerous practical examples are presented from around the world. The final chapter "Unexpected ground conditions and how to avoid them" presents cases of diverse difficult conditions. Black-and-white illustrations and photos are abundant and complement each subject nicely.

Each chapter contains straightforward didactic boxes that focus either on a case in point, good working practices or key terms of relevance to each topic. The book also includes an appendix with widely used soil and rock terminology for description and classification for engineering purposes and another appendix containing examples of borehole and trial pit logs from the UK, Hong Kong and Australia. These serve to illustrate the variety of use in descriptive terms and classifications. Not only the references provided at the end of this book, but also Hencher's introduction to the career pathways and an appendix describing international training, institutions and societies will be particularly useful to undergraduate and graduate students. 